\title{
Numerical analysis of hydroinertia gas bearings with inclined supply holes for high-speed rotary machines
}

\author{
Tomohiko Ise ${ }^{1}$, Sayuri Nakano ${ }^{1}$, Toshihiko Asami ${ }^{1}$, Yuki Endo ${ }^{2}$, Itsuro Honda ${ }^{1}$ \\ ${ }^{1}$ Graduate School of Mechanical Engineering, University of Hyogo, 2167 Shosha, Himeji, Hyogo 671-2280, Japan \\ ${ }^{2}$ JEOL RESONANCE Inc., 1-2, Musashino 3-Chome, Akishima, Tokyo 196-8558, Japan
}

Email address:

ise@eng.u-hyogo.ac.jp (T. Ise)

\section{To cite this article:}

Tomohiko Ise, Sayuri Nakano, Toshihiko Asami, Yuki Endo, Itsuro Honda. Numerical Analysis of Hydroinertia Gas Bearings with Inclined Supply Holes for High-Speed Rotary Machines. International Journal of Mechanical Engineering and Applications.

Vol. 2, No. 4, 2014, pp. 52-57. doi: 10.11648/j.ijmea.20140204.12

\begin{abstract}
Hydroinertia gas journal bearings have been applied to solid-state nuclear magnetic resonance (NMR) as an example. This type of bearing can realize a stable operation for the ultra-high-speed rotation of an NMR sample tube as high as several million rpm, because these bearings utilize a large radial clearance compared with conventional externally pressurized bearings. To obtain even higher rotational speeds, inclined supply holes in the direction of shaft rotation have been proposed. The characteristics of these proposed bearings are examined in this study by numerical analysis because the actual NMR sample rotor is thin and long (with a diameter of $1 \mathrm{~mm}$ to $4 \mathrm{~mm}$ ). The numerical analysis results of the hydroinertia journal bearings are reported in this study. Variation of the pressure distribution and the load capacity with respect to the effect of the radial clearance and the angle of the supply holes are described. The results show that a negative pressure is generated at large radial clearance, and the load capacity does not affect the angle. The pressure distribution was experimentally verified using a test rig, which has $10 \mathrm{~mm}$ diameter rotor.
\end{abstract}

Keywords: High-Speed Rotary Machines, Hydroinertia Gas Bearing, Pressure Distribution, Negative Pressure

\section{Introduction}

Hydroinertia gas journal bearings have been used in high-speed rotational machines such as those used in solid-state nuclear magnetic resonance (NMR) spectroscopy [1]. This type of bearing has inherent orifice restrictors and a large radial clearance compared with conventional externally pressurized gas journal bearings. The large radial clearance makes these bearings suitable for use with a rapidly rotating sample tube (shaft) as instabilities are suppressed by the reduction in hydrodynamic effects. For example, a $2 \mathrm{~mm}$ diameter shaft rotates at over 2,200,000 rpm. In addition, this configuration brings easy assembling. The $\mathrm{DN}$ value (expressed as the product of the shaft diameter $(\mathrm{mm})$ and the rotational speed (rpm)) exceeds 4,500,000. This type of bearing is also used for the study of micromachines and a palmtop gas turbine generator. Isomura et al., [2,3] evaluated the use of these bearings for micromachines, and achieved a rotational speed of 770,000 rpm using $4 \mathrm{~mm}$ diameter shaft (with a DN value of $3,080,000$ ). Tanaka et al.
$[4,5]$ tested the use of these bearings for a palmtop gas turbine generator, and achieved a rotational speed of $890,000 \mathrm{rpm}$ using a $4 \mathrm{~mm}$ diameter shaft (with a DN value of $3,560,000)$.

A method for calculating the pressure distribution in this bearing was presented by Hikichi et al. [6,7]. This method uses a circular thrust bearing surface to replace the radial surface for each supply hole. However, a problem exists with the theory of this method, in that, there is a possibility that the flow returns to laminar flow from turbulent flow. This contradicts the law of entropy increase of fluid dynamics. Yoshimoto et al. numerically and experimentally investigated the characteristics of an equivalent circular thrust surface [8], and the calculated and experimental results of this study were in good agreement. Presently, there are no analytical studies treating the overall journal bearing surface.

Recently, to obtain higher rotational speeds, hydroinertia gas bearings with supply holes inclined in the direction of rotation have been presented [9]. In this bearing, viscous frictional loss is thought to be reduced, as this mechanism 
provides gas flow in the rotational direction. In a previous study, Bennett and Marsh studied the behavior of externally pressurized gas journal bearings with inclined supply holes and compared them to conventional gas journal bearings [10]. They reported that the whirl onset speed with the supply holes inclined in the rotational direction increased compared with the conventional supply-type bearing. Tondl studied externally pressurized gas journal bearings with supply holes that were inclined in the direction opposite to the rotational direction [11]. Their studies addressed hydrostatic gas journal bearings only. For this reason, the characteristics of this supply mechanism using inclined supply holes, such as pressure distribution and load capacity for hydroinertia gas journal bearings, are not clear at this time.

This study presents numerical analysis results for a journal bearing surface in conjunction with inclined supply holes to verify the basic bearing characteristics. The modeled target bearing diameter is $2 \mathrm{~mm}$, which is an often used value. The characteristics investigated include shifting radial clearance, supply hole angle, and number of supply holes. To verify the analyzed results, measurements of the pressure distribution were conducted using a test rig. A testing rig with a bearing diameter of $10 \mathrm{~mm}$ was employed for the measurements, as a $2 \mathrm{~mm}$ diameter bearing is too small for adequate experimental evaluation.

\section{Characteristics of Hydroinertia Gas Bearings}

A schematic of conventional externally pressurized and hydroinertia gas bearings is shown in Fig. 1. Both bearings have inherent orifice restrictors. The hydroinertia gas journal bearing (Fig. 1(b)) has a large radial clearance compared with a conventional bearing (Fig. 1(a)) with the same circumference. As a result, the inertial force of the gas is dominant, and supersonic gas flow, shock waves, and negative pressure occur. This type of bearing has been used for solid-state NMR. The large radial clearance is thought to be the optimum structure because the shaft is taken in and out frequently. A $2 \mathrm{~mm}$ outer diameter hollow rotor rotates at over 2,200,000 rpm (for a DN value of 4,500,000) in actual devices.

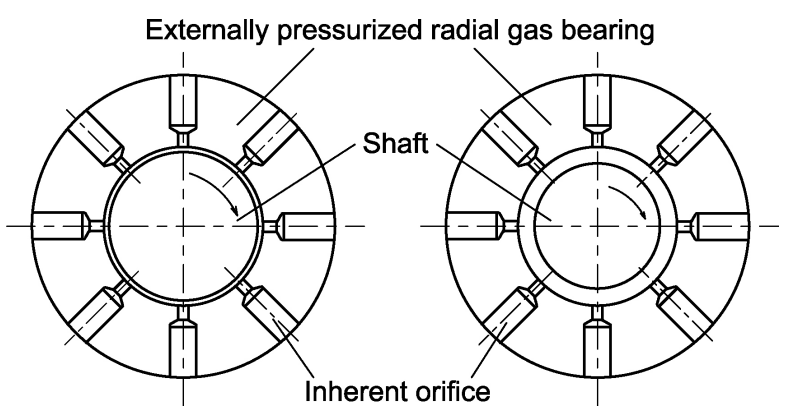

(a) Conventional

(b) Hydroinertia

Figure 1. Configurations of an externally pressurized gas journal bearing and a hydroinertia journal gas bearing.

\section{Proposed Bearing Configuration}

The proposed bearing configuration in this study is shown in Fig. 2(b), which also shows the conventional bearing in Fig. 2(a) for comparison. The proposed bearing has inclined supply holes in the direction of shaft rotation. In other words, the supply holes have an offset angle. It is thought that this mechanism produces more torque due to gas flow in the radial clearance compared with the conventional bearing. In a previous study, the authors attempted to calculate the pressure distribution of the proposed bearing using a method developed by Hikichi et al. [6,7]. The calculations were often unstable, and results were only obtained for certain specific conditions. Additionally, there is some concern about the reliability of these results, and for this reason, this study is based on computational fluid dynamics (CFD) analysis.

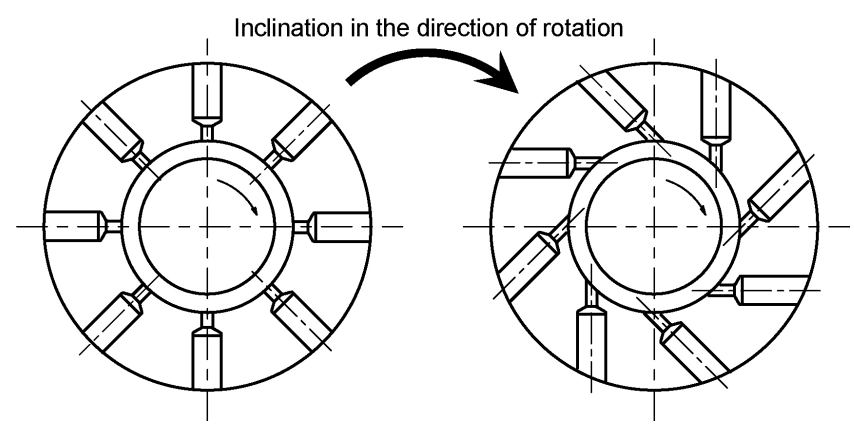

Figure 2. Bearing model of the proposed hydroinertia journal gas bearing.

\section{Validation of the Analysis}

To determine the performance of this bearing under inclined supply conditions, a general purpose CFD solver was employed. This study used STAR-CCM+. The analytical model was constructed using three-dimensional computer-aided design. Before performing the proposed bearing analysis, validation of the computational accuracy was first necessary. This was conducted using a thrust bearing model with a single supply hole. This analysis used polyhedral mesh as element type. Computational domain is inherent orifice part and bearing clearance part. The results were compared with those of Yoshimoto et al. [8]. The model used to determine the pressure distributions is shown in Fig. 3(a). Pressurized gas is supplied from the supply hole (open circle 1 in Fig. 3(a)) and the gas flows out to the atmosphere (open circle 2) through the circular thrust bearing surface. The dimensions of the analysis model are as follows: the outer diameter $D=6 \mathrm{~mm}$, the supply hole diameter $d=0.2 \mathrm{~mm}$, the dimensionless supply pressure $P=$ 6 , and the clearance $C_{r}=0.028 \mathrm{~mm}$. The dimensionless supply pressure $P=p_{s} / p_{a}$ is expressed as the supply gas pressure $p_{s}$ relative to the ambient pressure $p_{a}$. These are the same dimensions used by Yoshimoto et al. Boundary conditions were set as follows. Compressible fluid and turbulent flow condition are applied. Pressurized gas was supplied to inherent orifice inlet and atmosphere pressure 
was set at edge of bearing clearance. In the orifice inlet, flow velocity was set low speed $(0.01 \mathrm{~m} / \mathrm{s})$ because modeled sectional area of the inlet of upper stream is large. The analysis results are shown in Fig. 4. The horizontal axis represents the dimensionless radius $R$ of the bearing area, where $R=0$ indicates the center of the bearing surface and $R=1$ indicates the edge of the bearing surface. The broken line represents the position of the outer radius of the supply hole. The red line represents the results of the present study. The supplied pressure decreases to a negative pressure at the outlet of the supply hole, and subsequently, the pressure decreases to atmospheric pressure to recover to positive pressure. This distribution is in good agreement with the results of Yoshimoto et al., and the accuracy of the present analysis is validated from this study.
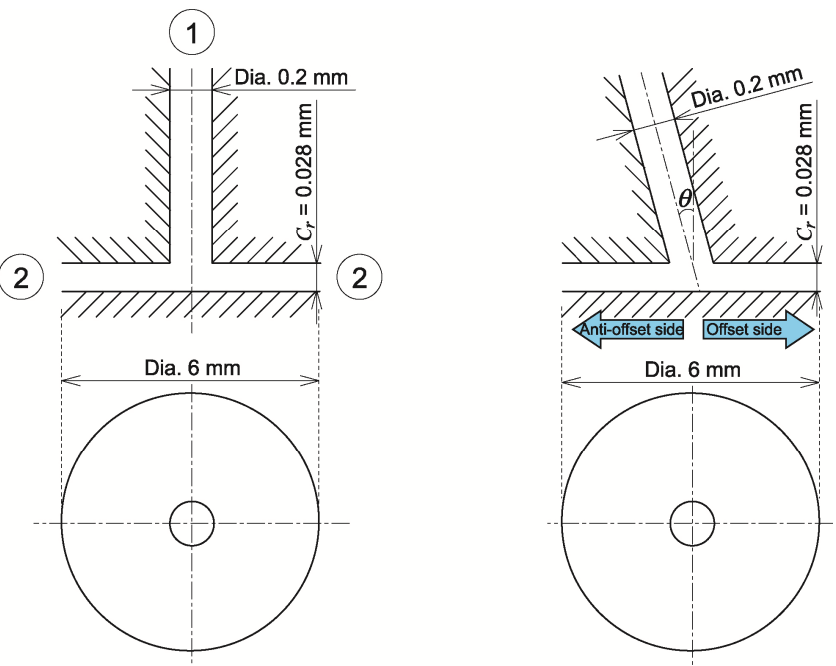

Figure 3. Analysis model for validation of the hydroinertia thrust gas bearing.

\section{Analysis of Bearing Pressure Distribution with Inclined Supply Holes}

\subsection{Thrust Bearing Model}

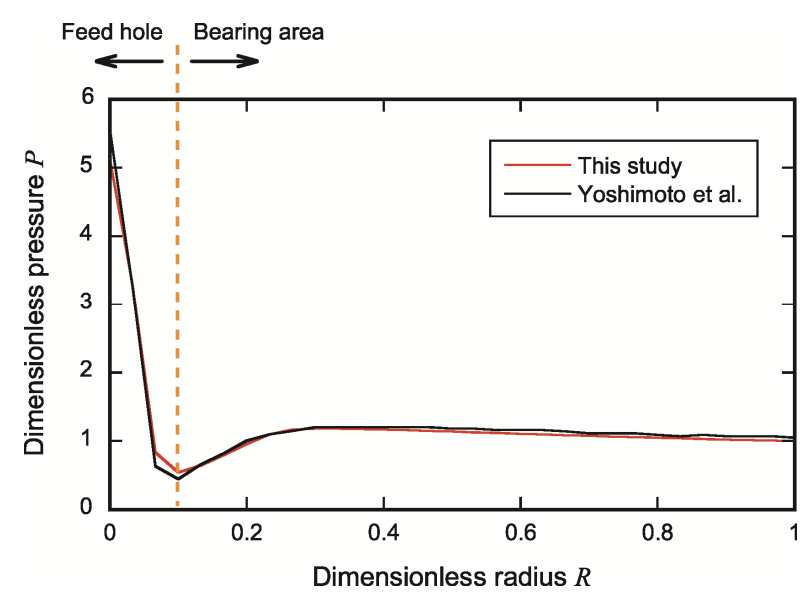

Figure 4. Analysis result of the hydroinertia thrust gas bearing.
Figure 3(b) shows the analysis model for the thrust bearing proposed in this study. The gas flow is the same as that in Fig. 3(a). The inclination angle of the supply hole is defined as the angle $\theta$ from the normal direction. In the present study, inclination angles of $\theta=0^{\circ}$ and $60^{\circ}$ are analyzed.

The results for $\theta=60^{\circ}$ at the bearing surface are shown in Fig. 5, which shows the view from the gas inlet. The contour represents the pressure magnitude. The dimensions and conditions are the same as those described in the previous section. The gas pressure is high in the supply hole; the outflow gas pressure from the supply hole decreases at the bearing surface, and a negative pressure occurs around the supply hole for all conditions and the pressure increases to atmospheric pressure. For $\theta=0^{\circ}$, the pressure is concentrically distributed. For $\theta=60^{\circ}$, a large negative pressure can be observed on the offset side. From these results, it can be observed that the inclination angle affects the asymmetry of the bearing surface pressure distribution.
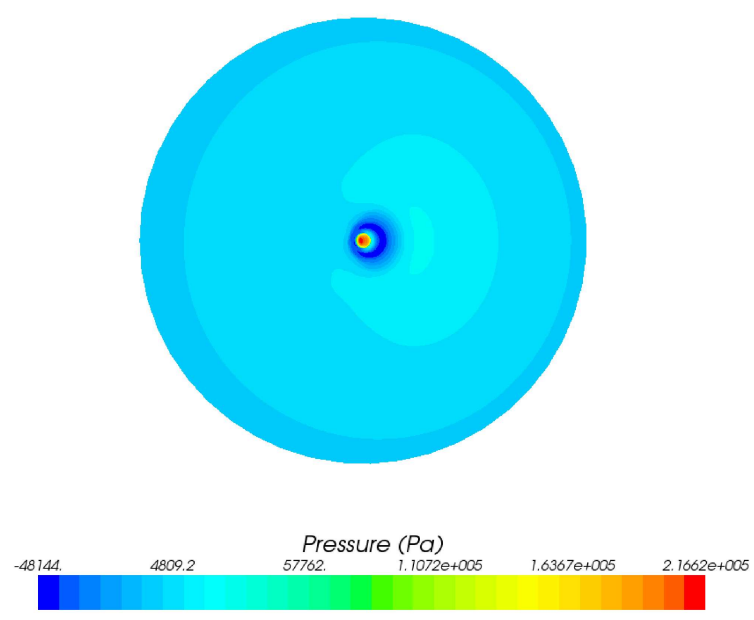

Figure 5. Analyzed pressure distribution of the thrust bearing surface with inclined supply holes $\left(\theta=60^{\circ}\right)$

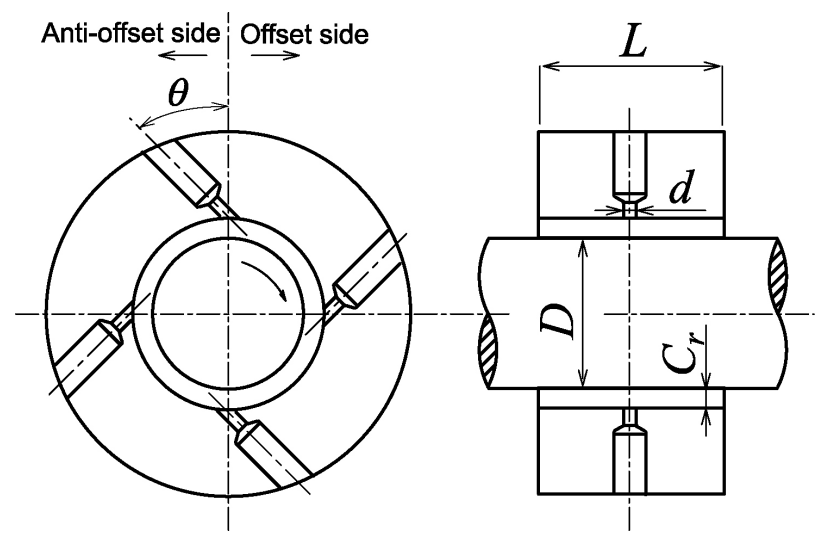

Figure 6. Analysis model of the hydroinertia gas journal bearing with inclined supply holes.

\subsection{Journal Bearing Model}

Based on the results for the thrust bearing in the former 
section, an analysis of the journal bearing surface was performed. This analysis investigated the effects of adjacent inclined supply holes on the pressure distribution. The model is shown in Fig. 6. A single-row admission-type bearing was used. This configuration is the same as that used in practical NMR. The dimensions of the analysis model are as follows: the bearing diameter $D=2 \mathrm{~mm}$, the bearing length $L=2 \mathrm{~mm}$, the supply hole diameter $d=0.3 \mathrm{~mm}$, the number of supply holes $n=4$, the dimensionless supply pressure $P=3$, and the clearance $C_{r}=0.0175 \mathrm{~mm}$. In this study, non-dimensional parameter called as gas feeding parameter $\Gamma$ was used. The $\Gamma$ is given by following formula[12]:

$$
\Gamma=\frac{24 \mu k C_{f} r_{s} \sqrt{R_{g} T}}{p_{a} C_{r}^{2}}
$$

where, the $\mu$ is gas viscosity the $k$ is number of gas supply hole, the $C_{f}$ is flow rate constant, $r_{s}$ is feed hole diameter, the $R_{g}$ is gas constant, the $T$ is gas temperature, the $p_{a}$ is atmospheric pressure and the $C_{r}$ is radial clearance of the baring. Similar flow rate can be produced by matching this parameter although both dimensions are different. In $C_{r}=$ $0.0175 \mathrm{~mm}$ condition, $\Gamma$ becomes 2.03 . This values are also used in latter section to compare the pressure distribution with the experiments. Angles of $\theta=0^{\circ}$ to $60^{\circ}$ with a step of $10^{\circ}$ were investigated. A static condition was used for this analysis, i.e., the rotor did not rotate. In addition, the rotor eccentricity ratio $\varepsilon$ was set at 0.4 . The parameter $\varepsilon$ is expressed as $\varepsilon=e / C_{r}$, where $e$ represents the displacement of the shaft from the bearing center, that is, $\varepsilon=0$ indicates that the rotor and the bearing centers are coincident. If $C_{r}$ is constant, increase of $\varepsilon$ means increasing displacement $e$. Values for the parameter $\varepsilon$ are defined such that the bottom side shown in Fig. 6 is positive.

Figure 7 shows the pressure distribution for $\theta=0^{\circ}$. A shaft displacement in the lower direction indicates that the lower radial clearance (eccentric side) is small and the opposite side clearance is large. On the eccentric side, the supplied pressure is maximum at the outlet of the supply hole, and the pressure monotonically decreases to ambient pressure. The distribution shows that positive pressure only occurs on the eccentric side, whereas negative pressure occurs on the opposite side.

The velocity vectors and the pressure distribution around one supply hole are shown in Fig. 8. These results represent results for $\theta=60^{\circ}$, and the velocity and pressure are asymmetrical in the circumferential direction. This asymmetry is observed to increase with increasing inclination angle. A higher gas velocity can be observed on the offset side compared with the anti-offset side. At the exit of the supply hole, a high positive pressure can be observed on the anti-offset side, which is consistent with the velocity results. This phenomenon occurs regardless of the inclination angle of the supply holes. It is thought that the gas pressure affects only a local area around the supply holes due to the large radial clearance in these bearings. However, as these results apply only to the case in which the shaft is not rotating, it will be necessary to conduct a further analysis under high-speed rotation conditions.

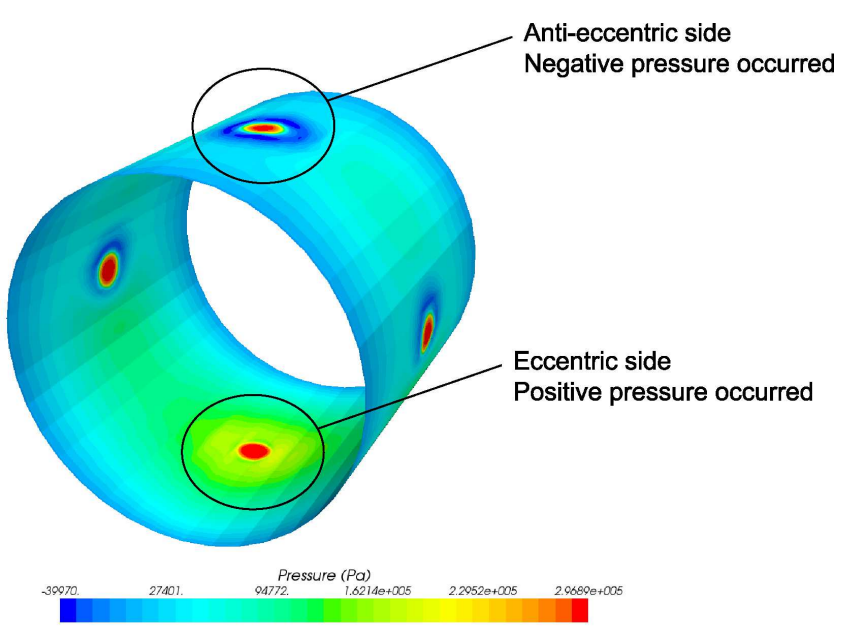

Figure 7. Pressure distribution of the $\theta=0^{\circ}$ supply holes and $\varepsilon=0.4$

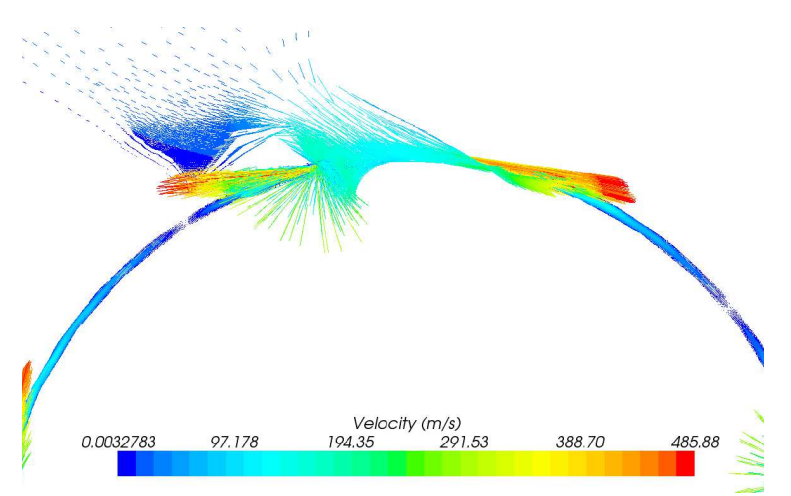

(a) Velocity vectors

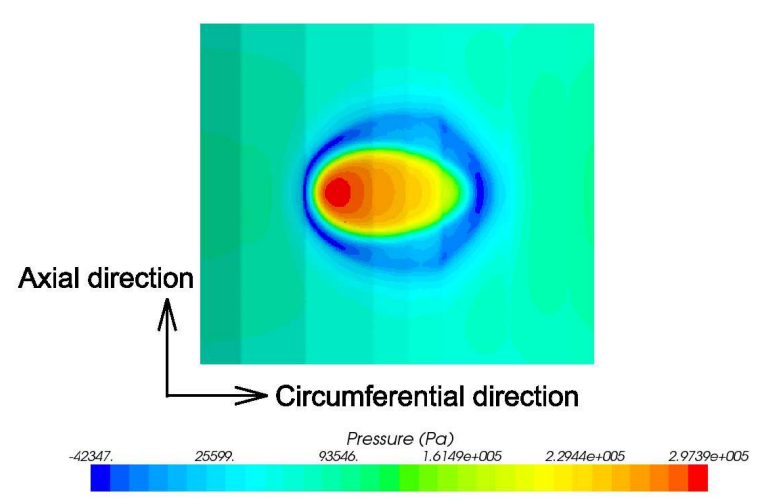

(b) Pressure distribution

Figure 8. Velocity vectors and the pressure distribution around a single inclined supply hole of $\theta=60^{\circ}$.

Static load capacity was calculated by shifting the supply hole angles with radial clearance. This suggests that vertical direction values are obtained by integrating the pressure over the entire bearing area. Figure 9 (a) shows the calculated results of the load capacity for $\varepsilon=0.2$. The horizontal and vertical axes represent the supply hole angle and load capacity $W$, respectively. The ordinate $W$ was expressed as 
dimensionless values in accordance with $W=w /\left(L D\left(p_{s}-p_{a}\right)\right)$, where $w$ is the dimensional load capacity. The three lines included represent different radial clearances. In this study, $C_{r}$ values of $0.014 \mathrm{~mm}(\Gamma=3.17), 0.0175 \mathrm{~mm}(\Gamma=2.03)$, and $0.0349 \mathrm{~mm}$ ( $\Gamma=0.51)$ were used. The chosen $C_{r}$ values indicate typical characteristics. Conditions of $0.014 \mathrm{~mm}$ and $0.0175 \mathrm{~mm}$ generate the same load capacity compared with that for $C_{r}=0.0349 \mathrm{~mm}$. Positive pressure only occurs in the condition of $C_{r}=0.014 \mathrm{~mm}$. This value of $W$ was confirmed by quantitative agreement with the numerical analysis using the divergence formulation method for this condition $[12,13,14,15]$. Negative pressure acts on the opposite side of the eccentricity for $C_{r}=0.0175 \mathrm{~mm}$, as mentioned above. It is possible that this causes the observed increase in the load capacity, that is, the effect of attractive and repulsive forces generates a large load capacity. The load capacity for $\varepsilon=0.4$ is shown in Fig. 9(b), which monotonically increases under all clearance conditions. The load capacity for the $C_{r}=0.0175$ condition is particularly enhanced by the action of the abovementioned positive and negative pressures. In addition, the load capacity is slightly influenced by the inclination angle of the supply holes.

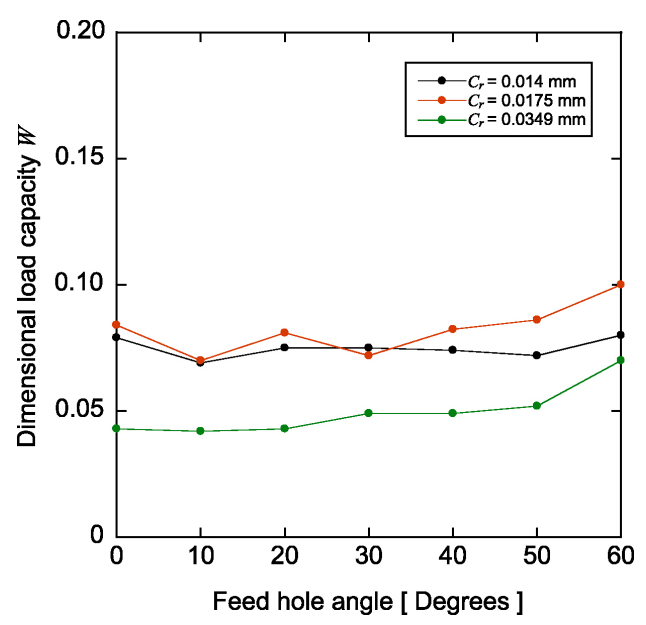

(a) $\varepsilon=0.2$

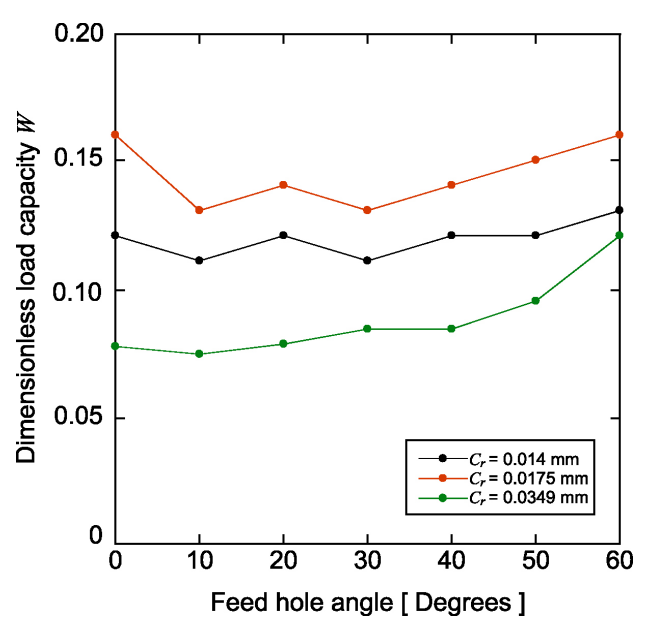

(b) $\varepsilon=0.4$

Figure 9. Load capacity of the hydroinertia gas journal bearing with inclined supply holes.

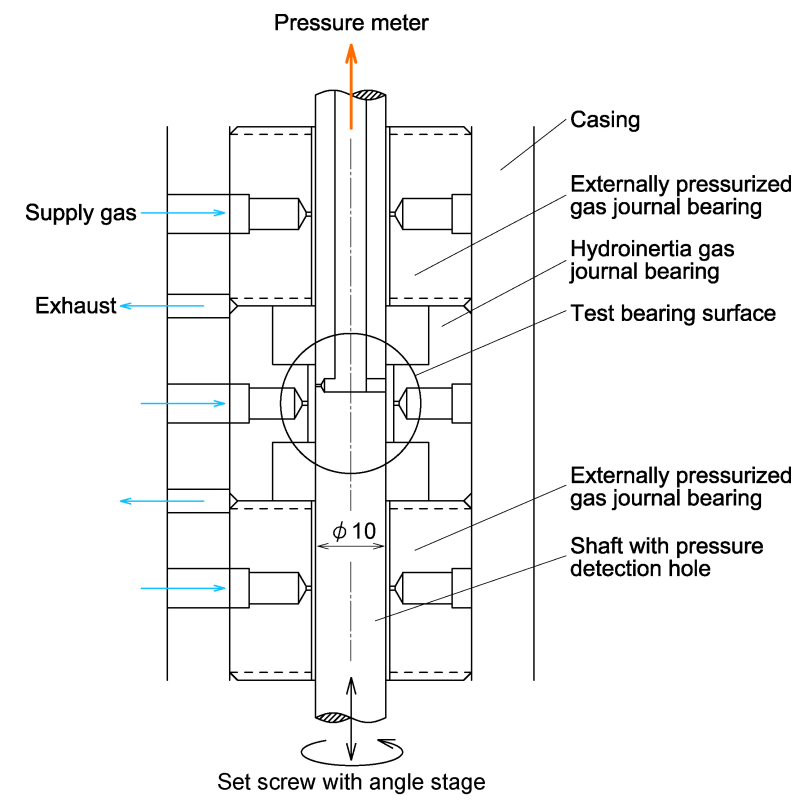

Figure 10. Experimental setup for measurement of the pressure distribution.

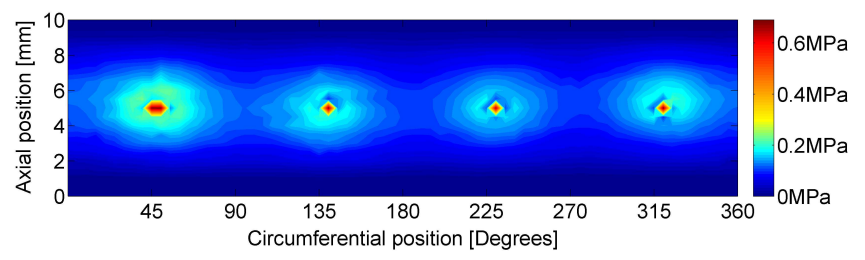

(a) $\theta=0$ degree

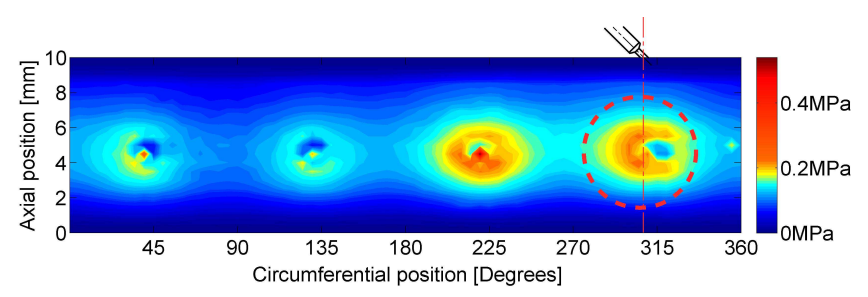

(b) $\theta=60$ degrees

Figure 11. Pressure distributions of the hydroinertia gas journal bearings.

\section{Measurement of the Pressure Distribution of the Bearings}

The pressure distribution of the bearing was measured using a test rig to qualitatively verify the results of the numerical analyses. This test was conducted using a $10 \mathrm{~mm}$ diameter bearing surface as the measurement is impractical at this time for a shaft diameter as small as $2 \mathrm{~mm}$.

The test rig is shown in Fig. 10. The bearings and shaft are evaluated vertically to eliminate the effects of the shaft mass. The test hydroinertia bearing is installed in the casing. The manufactured actual clearance $C_{r}$ is $0.020 \mathrm{~mm}$ and feed hole diameter is $0.4 \mathrm{~mm}$. This dimensions are selected considering ease of manufacturing. $\Gamma=2.07$ is obtained in this condition. It is coincides with analysis of former section. The supplied pressure is set at $P=6$. A shaft is installed in the bearing. A small orifice (diameter of 0.05 
$\mathrm{mm}$ ) is set in this shaft for pressure measurement. This small diameter enables measurement of the static pressure only. The position of the shaft with the orifice is controlled by a set screw and an angle fine adjustment stage. The detected pressure is measured by a semiconductor-type pressure sensor. The shaft is supported by conventional externally pressurized gas journal bearings placed on both sides of the test hydroinertia bearing to position the center of the bearing, i.e., to ensure that $\varepsilon=0$. The radial clearance of the externally pressurized gas journal bearings is set to $0.01 \mathrm{~mm}$. Grooves are provided to ensure that atmospheric pressure is provided at the border of the bearings. The load capacity is sufficiently large to support the shaft. The axial and circumferential directions are measured at $0.1 \mathrm{~mm}$ and $5^{\circ}$ intervals, respectively.

Figure 11 (a) shows the measured gauge pressure distributions of the test bearings for $\theta=0^{\circ}$. An isotropic pressure distribution was obtained, and a decrease in the pressure was confirmed near the supply hole. Figure 11(b) shows the pressure distributions for $\theta=60^{\circ}$. The supply hole angle for the bearing surface is also shown in this figure. Different pressure profiles are obtained depending on the supply hole considered. It is thought that the small eccentricity of the shaft in the bearing is the cause of the observed variation. An asymmetrical pressure distribution was obtained around the supply hole, indicated by the dashed red line circle, that is similar to the results of the numerical analysis. Furthermore, a decreased pressure was obtained locally on the offset side. A negative pressure was not observed under the two conditions considered. The obtained measurements demonstrate the same tendencies as those exhibited by the numerical analysis, and qualitative agreement is confirmed. However, a detailed parameter study is most likely necessary to clarify the characteristics of this bearing, and this will be carried out in the near future.

\section{Conclusion}

To obtain higher rotational speeds during practical NMR, hydroinertia gas bearings with supply holes inclined in the direction of rotation were proposed. This study performed a CFD analysis of hydroinertia thrust and journal bearings using a general purpose solver under static conditions. The results indicate that the load capacity is slightly influenced by the inclination angle of the supply hole. For $\theta=0^{\circ}$, the pressure distribution was symmetrical in each direction. An asymmetrical pressure distribution was obtained around the supply hole. The same phenomenon was obtained experimentally; however, a parameter study is necessary to clarify the characteristics of this bearing, and this will be carried out in the near future.

\section{References}

[1] Y. Nishiyama, Y. Endo, T. Nemoto, H. Utsumi, K. Yamauchi, K. Hioka, T. Asakura, "Very fast magic angle spinning 1H-14N 2D solid-state NMR: Sub-micro-liter sample data collection in a few minutes," Journal of Magnetic Resonance, Vol. 208, Issue 1, 2011, pp. 44-48.

[2] K. Isomura, S. Togo, K. Hikichi, S. Goto, S. Tanaka, "Analytical and Experimental Study of Hydroinertia Gas Bearings for micromachine Gasturbines," Proceedings of ASME Turbo Expo 2005, 2005, No. GT2005-68401.

[3] Isomura, K. et al., "Development of high-speed micro-gas bearings for three-dimensional micro-turbo machines," Journal of Micromechanics and Microengineering, 15, 2005, S222-227.

[4] S. Tanaka, K. Hikichi, S. Togo, M. Esashi, "Turbo test rig with hydroinertia air bearings for a palmtop gas turbine," Journal of Micromechanics and Microengineering, Vol. 14, 2004, pp. 1449-1454.

[5] S. Tanaka, M. Esashi, K. Isomura, K. Hikichi, Y. Endo, S. Togo, "Hydroinertia Gas Bearing System to Achieve $470 \mathrm{~m}$ per sec Tip Speed of 10 mm-Diameter Impellers," Transactions of ASME, Journal of Tribology, Vol. 129, 2007, pp. 655-659.

[6] K. Hikichi, K. Shiratori, S. Togo, K. Hikoka, "Hydroinertia Gas Bearings and Their Application to High Speed Micro Spinners," Journal of the Japanese Society of Tribologists, Vol. 50, No. 6, 2005, pp. 465-470.

[7] K. Hikichi, S. Goto, S. Togo, S. Tanaka, K. Isomura, "Hydroinertia gas bearings for micro spinners," Journal of Micromechanics and Microengineering, Vol. 15, 2005, pp. 228-232.

[8] S. Yoshimoto, M. Yamamoto, K. Toda, "Numerical Calculations of Pressure Distribution in the Bearing Clearance of Circular Aerostatic Thrust Bearings with a Single Air Supply Inlet," Transactions of ASME, Journal of Tribology, Vol. 129, Issue 2, 2007, pp. 384-390.

[9] S. Nakano, T. Ise, T. Asami, "Calculation of the Characteristics and its Verification of the Hydroinertia Gas Bearings with Inclined Supply Holes," Proceedings of the 12th Machine Design and Tribology Division Meeting in JSME, 2012, pp. 79-80 (in Japanese).

[10] J. Bennett, H. Marsh, "The Steady State and Dynamic Behavior of the Turbo-Bearing," Proceedings of the 6th International Gas Bearing Symposium, 1974, Paper No. C4.

[11] A. Tondl, "Bearings with a Tangential Gas Supply," Proceedings of Gas Bearing Symposium, University of Southampton, 1967, Paper No. 4.

[12] H. Yabe, "A study on Run-out Characteristics of Externally pressurized Gas Journal Bearing (1st Report, Modified DF Method for Point-Source Solution)," Transactions of the Japan Society of Mechanical Engineers Series C, 1992, Vol. 58, No. 548, pp. 1170-1176 (in Japanese with English abstract).

[13] S. Togo, Gas Bearing Design Guide Book, 2002, Kyoritsu Shuppan Co., Ltd. (in Japanese).

[14] S. Togo, I. Kawashima, T. Ise, K. Hikichi, Y. Endo, T. Maeda, Gas Bearing - Technics of design and operation and production-, 2014, Kyoritsu Shuppan Co., Ltd. (in Japanese).

[15] K. Czolczynski, Rotordynamics of Gas-Lubricated Journal Bearing Systems, 2010, Springer. 